\title{
Immunodiagnosis of chronic Chagas' disease using the Tc 46 and Tc 58 antigens
}

\author{
Imunodiagnóstico da doença de Chagas crônica \\ utilizando os antígenos Tc 46 e Tc 58
}

Valéria R.A. Pereira, Mineo Nakazawa, Veridiana C. Furtado, Frederico G.C. Abath and Yara M. Gomes

\begin{abstract}
The polypeptides of 46 and 58kDa were recognized in different T. cruzi strains (Y,WSL and Colombiana) by serum of all chagasic patients studied. These polypeptides were isolated from T. cruzi $Y$ strain and used in ELISA. The sensitivity and specificity were 97.6\% [CI 95\%:86100\%] and 100\% [CI 95\%: 89.3-100\%], respectively when Tc 46 was used. When Tc 58 was used the sensitivity and specificity were 100\% [Cl 95\%: 89.6-100\%] and 90.2\% [Cl 95\%: 75.9-96.8\%], respectively.

Key-words: T. cruzi. Insoluble antigens. Immunodiagnosis. Chagas' disease.

Resumo Os polipeptídeos de 46 e 58kDa foram reconhecidos em diferentes cepas de T. cruzi (Y,WSL e Colombiana) pelo soro de todos os pacientes chagásicos estudados. Estes polipeptídeos foram isolados da cepa $Y$ e usados em ELISA. A sensibilidade e especificidade foram $97,6 \%[\mathrm{Cl}$ 95\%: 86-100\%] e 100\% [CI 95\%: 89,3-100\%], respectivamente quando Tc 46 foi usada. Quando Tc 58 foi utilizada a sensibilidade e especificidade foram de 100\% [Cl 95\%: 89,6-100\%] and 90,2\% [Cl 95\%: 75,9-96,8\%], respectivamente.
\end{abstract}

Palavras-chaves: T. cruzi. Antígenos insolúveis. Imunodiagnóstico. Doença de Chagas.

In the acute phase of Chagas' disease, when parasitemia is high, usually diagnosis can be easily made using conventional parasitological methods (thin blood smear, thick blood smear, fresh blood examination). During the chronic phase, due to the low parasitemia, diagnosis is usually performed by immunological methods in conjunction with clinical epidemiological evidence. Indirect immunofluorescence, indirect hemagglutination and ELISA are widely used in Latin America for individual diagnosis and for screening donated blood, as well as in epidemiological studies.
The antigens commonly used in serodiagnosis of Chagas' disease are fixed epimastigote forms or complex mixtures of proteins and glycoconjugates extracted from whole parasites which lead to false positive results due to cross-reactions with other parasites. In the last years, several research groups have tried to develop new diagnostic tests employing purified antigens, recombinant proteins or synthetic peptides in order to achieve a more reproducible and specific diagnosis of Chagas' disease ${ }^{23589}$. Thus, the use of chemically defined antigens and the molecular and

Departamento de Imunologia do Centro de Pesquisas Aggeu Magalhães/FIOCRUZ, Recife, PE This work was partially funded by CAPES, FACEPE and FIOCRUZ

Address to: Dr Yara M. Gomes, CPqAM/FIOCRUZ. Av. Moraes Rego s/n, Cidade Universitária, 50670-420 Recife, PE, Brasil.

Fax: 5581 453-2449.

e-mail: yara@cpqam.fiocruz.br

Recebido para publicação em 11/11/99. 
immunological characterization of the relevant parasite antigens are of utmost importance. To be useful, these antigens should be common to all known T. cruzi strains and should not cross react with sera from patients carrying other diseases ${ }^{10}$.

In the present communication we report on two polypeptides ( 46 and $58 \mathrm{kDa}$ ), present in the insoluble antigenic fraction of different $T$. cruzi strains that were recognized by all chagasic patients studied. In addition, we evaluate their usefulness for the ELISA diagnosis of human chronic Chagas' disease.

Serum samples were collected from 42 patients with chronic Chagas' disease: cardiac form $(n=14)$, asymptomatic form $(n=21)$, digestive form $(n=2)$ and mixed form $(n=5)$. Diagnosis of chronic Chagas' disease was based upon the collective analysis of a set of elements: clinical manifestations and electrocardiographic alterations, compatible epidemiological history, and a positive reaction by two different serological tests. In addition, serum of patients with other parasitic diseases, such as: visceral $(n=6)$ and cutaneous $(n=9)$ leishmaniasis, toxoplasmosis $(n=9)$, schistosomiasis (7), filariasis (5) and malaria (5), as well as sera from healthy individuals $(n=5)$ from non endemic areas, were also analysed. Sera were stored at $-20^{\circ} \mathrm{C}$ until use.

Epimastigote forms of three different strains of $T$. $\operatorname{cruzi}(\mathrm{Y}=$ Type I, $\mathrm{WSL}=$ Type II and Colombiana $=$ Type III) were used. These forms were obtained by cultures in RPMI 1640 medium containing $10 \%$ calf serum. Parasites were grown at $26^{\circ} \mathrm{C}$ by serial passages at every $7^{\text {th }}, 14^{\text {th }}$ and $21^{\text {st }}$ day for $Y$, Colombiana and WSL strains, respectively when they were harvested and washed 6 times $(2500 \times \mathrm{g}, 15 \mathrm{~min})$ with $150 \mathrm{mM}$ PBS pH 7.2 containing proteases inhibitors ( $1 \mathrm{mM}$ PMSF and $1 \mathrm{mM}$ EDTA). Parasites were ressuspended in $10 \mathrm{ml}$ of deionized water containing the same concentration of proteases inhibitors, sonicated 5 times (30 sec pulses) on ice (Ultrasonic Homogenizer, Model CP $501-$ Cole Parmer) and centrifuged at $10^{5} \times \mathrm{g}$ for $1 \mathrm{~h}$. Protein concentration of the pellet (insoluble antigens) was determined according to Lowry ${ }^{7}$.

Twelve $\mu \mathrm{g}$ of the insoluble antigen fraction, corresponding to each $T$. cruzi strain were separated in polyacrylamide gels $(10 \%)$ according to Laemmli ${ }^{6}$ using a mini-gel system (Hoefer Scientific Instruments, San Francisco,
USA). Proteins were transferred from the gel to a nitrocellulose sheet (pore size $=0.45 \mathrm{~mm}$ ) with a semi-dry blotter at $30 \mathrm{~mA}$ during $60 \mathrm{~min}$. The sheets containing each of the antigens from the 3 strains were cut into vertical strips, which were treated with a solution of $5 \%$ defatted milk (Molico, Nestlé, São Paulo, Brazil), 0.05\% Tween 20 in PBS, pH 7.2 (PBS-Tw) for $2 \mathrm{~h}$ at room temperature with constant shaking. After washing the strips were incubated with serum samples from patients with Chagas' disease, diluted 1:100 in PBS-Tw. Individual sera of normal subjects from nonendemic area as well as of subjets with other parasitic diseases were used as controls. The bound antibodies were detected with peroxidaseconjugated goat anti-human IgG ( $\gamma$ chain specific). The immune complexes were revealed by addition of $\mathrm{H}_{2} \mathrm{O}_{2}$ and 4-chloro-1-naphthol. Colour development was stopped by washing in distilled water.

The reactivity patterns showed by patients with Chagas' disease are presented in Figure 1. At least 23 polypeptides with molecular weights of 14 to $145 \mathrm{kDa}$ could be identified. The intensity of the reaction to different antigens was variable but similar patterns of reactivity were observed with almost all analysed sera (Figure 1). No antigenic pattern characteristic of clinical forms was found. No reaction was observed when the sheet was incubated with normal human sera. The comparative analysis of the reactivity patterns of sera from Chagas' disease and other parasitic diseases indicates that at least 15 polypeptides specifically reacted with sera from chagasic patients. Among them, the 46 and $58 \mathrm{kDa}$ polypeptides reacted with sera from 42 Chagas' disease patients. The 16, 20, 29, 32, $33,34,35,40,44,48,74,88$, and $145 \mathrm{kDa}$ polypeptides were recognized by sera from chagasic patients with variable frequency (data not shown). The 46 and $58 \mathrm{kDa}$ polypeptides were isolated by preparative electrophoresis according to Gomes et $\mathrm{al}^{4}$ and will be referred to as Tc 46 and Tc 58 antigens.

The Tc 46 and Tc 58 antigens isolated from $Y$ strain were diluted in $0.05 \mathrm{M} \mathrm{Na}_{2} \mathrm{CO}_{3}$ buffer, $\mathrm{pH}$ 9.6, and coated onto flat-bottomed microtitre plates. The optimum concentration (500ng/well) was determined by checkerboard titration using positive and negative sera. The specific $\lg G$ bound to these antigens was determined using a horseradish peroxidase-conjugated goat antihuman IgG. The development of the reaction was 
carried out with orthophenylenediamine-OPD and $\mathrm{H}_{2} \mathrm{O}_{2}$ and blocked with $2.5 \mathrm{M} \mathrm{H}_{2} \mathrm{SO}_{4}$. The optical density (OD) was measured at $490 \mathrm{~nm}$. Samples were recorded as positive according to the cutoff value, calculated as the mean OD of the negative controls plus two standard deviations (SD). The sensitivity and specificity were calculated according to Camargo ${ }^{1}$. The confidence interval was calculated at the level of $95 \%(\mathrm{Cl} 95 \%)$.

ELISA results are shown in Table 1. When Tc 46 was used as antigen 41 out of 42 chagasic patients were considered positive for Chagas' disease. No cross-reaction was observed with other parasitic diseases. Sensitivity and specificity were 97.6\% [Cl 95\%: 86-100\%] and 100\% [Cl 95\%: 89.3-100\%], respectively. When Tc 58 was used the sensitivity and specificity were $100 \%$ [CI 95\%: 89.6-100\%] and 90.2\% [Cl 95\%: 75.9-96.8\%], respectively (Table 1 ). These results are currently being further evaluated by testing a larger sample and combining both antigens. In addition, experiments are being carried out to clone the encoding genes.

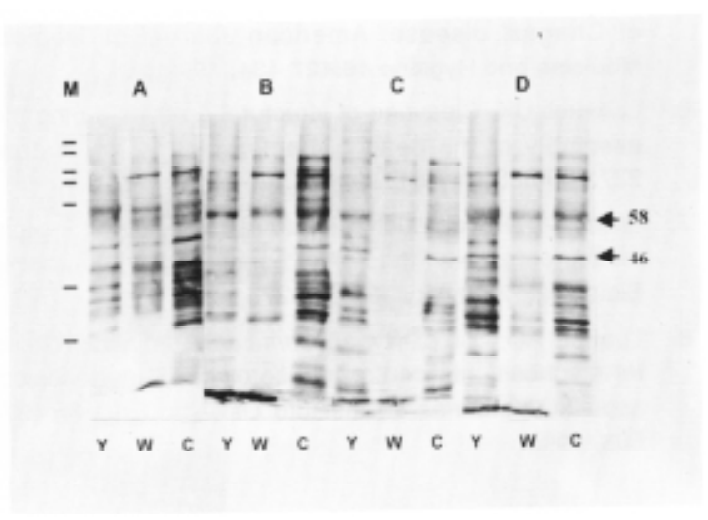

Figure 1 - Representative Western blot of the antigenic pattern recognized by sera of patients with different clinical forms of chronic Chagas' disease. A: cardiac form; B: asymptomatic form; $C$ : digestive form and $D$ : mixed form. $Y=Y$ strain; $W=W S L$ strain; $C=$ Colombiana strain Molecular weight markers $(M)$ on left indicate the numbers 211, 119, 98, 80.6, 64.4, 44.6 and $38.9 \mathrm{kDa}$. Arrow on right indicate TC46 and TC 58 antigens.

Table 1 - Reactivity of Tc 46 and Tc 58 antigens in ELISA with different human sera.

\begin{tabular}{lcc}
\hline Sera & Tc 46 & Tc 58 \\
\hline Chagasic $(n=42)$ & 41 & 42 \\
Negative $^{*}(n=5)$ & 0 & 0 \\
Visceral leishmaniasis $(n=6)$ & 0 & 0 \\
Cutaneous leishmaniasis $(n=9)$ & 0 & 1 \\
Toxoplasmosis $(n=9)$ & 0 & 0 \\
Malaria $(n=5)$ & 0 & 3 \\
Schistosomiasis $(n=7)$ & 0 & 0 \\
Filariasis $(n=5)$ & 0 & 0 \\
\hline
\end{tabular}

${ }^{*}$ Negative sera were from healthy individuals from non endemic areas.

\section{AKNOWLEDGMENTS}

We thanks to Dr Jarbas Malta for selecting patients and Wayner Souza for performing the statistical analysis.

\section{REFERENCES}

1. Camargo ME. An appraisal of Chagas' disease serodiagnosis. In: Wendel S, Brener Z, Camargo ME, Rassi A (eds) Chagas' disease (American Trypanosomiasis): its impact on transfusion and clinical medicine. International Society of Blood Transfusion Brazil' 92 Cartgraf, São Paulo, p 165-168, 1992.

2. Goldenberg S, Krieger MA, Lafaille JJ, Almeida E, Oelemann W. Use of Trypanosoma cruzi recombinant antigens in the immunological diagnosis of Chagas' disease. Memórias do Instituto Butantan 53(supl 1):7176, 1991.
3. Gomes YM. PCR and sero-diagnosis in chronic Chagas'disease: biotechnological advances. Applied Biochemistry and Biotechnology 66:107-119, 1997.

4. Gomes YM, Abath FGC, Nakazawa M, Minoprio P, Vouldoukis I, Monjour L. Partial protection against Trypanosoma cruzi after immunizing with the Tc Y 72 antigenic preparations. Memórias do Instituto Oswaldo Cruz 92:167-172, 1999.

5. Krieger MA, Almeida E, Oelemann W, Lafaille JJ, Pereira JB, Krieger H, Carvalho MR, Goldenberg S. Use of recombinant antigens for the accurate immunodiagnosis 
of Chagas' disease. American Journal of Tropical Medicine and Hygiene 46:427-434, 1992.

6. Laemmli UK. Cleavage of structural proteins during the assembly of the head of bacteriophage T4. Nature 227:680-685, 1970.

7. Lowry OH, Rosebrouch NJ, Farr AL, Randall RJ. Protein measurement with the Folin Phenol reagent. Journal of Biological Chemistry 193:263-275, 1951.

8. Luquetti AO. Use of Trypanosoma cruzi defined proteins for diagnosis-multicentre trial serological and technical aspects. Memórias do Instituto Oswaldo Cruz 85:497505, 1990.
9. Umezawa ES, Bastos SF, Camargo ME, Yamauchi M, Santos MR, Gonzalez A, Zingales B, Levin MJ, Souza O, Rangel-Aldao R, Franco da Silveira J. Evaluation of recombinant antigens for serodiagnosis of Chagas' disease in South and Central America. Journal Clinical Microbiology 37:1554-1560, 1999.

10. Zingales B, Gruber A, Ramalho CB, Umezawa ES, Colli W. Use of recombinant proteins of Trypanosoma cruzi in the serological diagnosis of Chagas' disease. Memórias do Instituto Osvaldo Cruz 85:519-522, 1990. 